\title{
Associations between metabolic syndrome and gynecologic cancer
}

\author{
Da Yong Lee, MD'1, Taek Sang Lee, MD, PhD² \\ Department of Obstetrics and Gynecology, ${ }^{1}$ Kyungpook National University Hospital, College of Medicine, Kyungpook National University, Daegu, \\ ${ }^{2}$ Seoul Metropolitan Government-Seoul National University Boramae Medical Center, Seoul, Korea
}

Metabolic syndrome (MetS) is a group of risk factors that causes cardiovascular and diabetic morbidity and mortality, which is diagnosed by central obesity, dyslipidemia, hyperglycemia, and hypertension. Increasing epidemiological data and experimental results indicate that the presence of MetS increases the incidence of common malignancies and related mortality. Epidemiological studies have previously reported an association of endometrial cancer occurrence with MetS. Aromatization of androstenedione to estrogen, insulin resistance, and diabetes can cause increased levels of free estrogen, and the detrimental effect of elevated estrogen as a carcinogen is well studied in endometrial cancer. Medications used to manage MetS such as metformin and statins are suggested to reduce endometrial cancer risk and improve survival. Some large population-based epidemiological studies have suggested that the MetS is related to an increased risk of cervical carcinoma. MetS may contribute to viral-host interactions, which lead to persistent human papilloma virus (HPV) infection, although limited epidemiological data are available. Specific effects of obesity and diabetes on the occurrence of ovarian cancer have been suggested. However, the direct correlation between MetS and ovarian cancer is still lacking. Previous retrospective studies reported that the use of metformin, statins, and beta-blockers could be associated with cancer prevention or better prognosis. Proper diagnosis and management of the MetS should be a part of the strategies undertaken to prevent and treat gynecologic cancer. So far, only limited data is available on this subject, and further clinical and fundamental research is required to further clarify the effect of these therapies on gynecologic cancer treatment.

Keywords: Metabolic syndrome; Endometrial cancer; Cervical cancer; Ovarian cancer

\section{Introduction}

Incidence of metabolic syndrome (MetS) is increasing worldwide and is becoming an important clinical problem and public health concern in many countries. Economic development, sedentary lifestyle, and westernized dietary patterns are factors affecting the prevalence of MetS. This environment contributes to obesity as seen in many developing and developed countries. MetS is a group of risk factors for cardiovascular complications and diabetes having insulin resistance as the major principal feature. In addition, chronic proinflammatory status is the accompanying underlying characteristic [1]. The diagnostic criteria define MetS as expressing 3 or more of the 5 risk factors: 1) central obesity defined by waist circumference, 2) hyperglycemia, 3) high triglyceride level, 4) low high-density lipoprotein cholesterol level, and 5) hypertension. The World Health Organization (WHO) suggested a clinical definition for MetS in 1998. Since then, several modified definitions have been proposed for the diagnosis of MetS. Among them, the Adult Treatment Panel III of the National Cholesterol Education Program (NCEP-ATP III) definition has been widely accepted. According to this criteria, MetS is diagnosed as follows: 1) waist circumference: $\geq 102 \mathrm{~cm}$ in men and $\geq 88 \mathrm{~cm}$ in women $(\geq 90 \mathrm{~cm}$ in men and

Received: 2019.12.04. Revised: 2020.01.01. Accepted: 2020.01.16. Corresponding author: Taek Sang Lee, MD, PhD

Department of Obstetrics and Gynecology, Seoul Metropolitan Government-Seoul National University Boramae Medical Center, 20 Boramae-ro 5-gil, Dongjak-gu, Seoul 07061, Korea

E-mail: tslee70@gmail.com

https://orcid.org/0000-0001-8119-5601

Articles published in Obstet Gynecol Sci are open-access, distributed under the terms of the Creative Commons Attribution Non-Commercial License (http://creativecommons. org/licenses/by-nc/3.0/) which permits unrestricted non-commercial use, distribution, and reproduction in any medium, provided the original work is properly cited.

Copyright $\odot 2020$ Korean Society of Obstetrics and Gynecology 


\section{Obstetrics \& Gynecology Science}

Vol. 63, No. 3, 2020

$\geq 80 \mathrm{~cm}$ in women according to the International Obesity Task Force criteria for the Asian-Pacific population), 2) fasting blood glucose $\geq 110 \mathrm{mg} / \mathrm{dL}$ (includes anti-diabetic medications), 3) triglycerides $\geq 150 \mathrm{mg} / \mathrm{dL}$, 4) high-density lipoprotein (HDL)-cholesterol $<40 \mathrm{mg} / \mathrm{dL}$ in men and $<50 \mathrm{mg} / \mathrm{dL}$ in women, 5) blood pressure $\geq 130 / 85 \mathrm{mmHg}$ (includes antihypertensive medications) [2].

There is increasing epidemiological evidence suggesting that MetS elevates the risk of several common cancer types and cancer-related morbidity and mortality [3]. In women, these cancer types include breast cancer, colon cancer, gastric cancer, esophageal cancer, pancreatic cancer, renal cancer, and hepatic cancer. Theories that contribute to this phenomenon suggest that the chronic inflammatory status and oxidative stress associated with the components of MetS, as well as synergistic effects among the metabolic detrimental effects increases the carcinogenesis risk more than each individual component of MetS [3].

In addition to well-established breast cancer, the relationship between various gynecologic cancers and MetS has also been identified. Most of the preceding reports were related to endometrial cancer, but recent studies suggest that cervical and ovarian cancers are also associated with MetS. The purpose of this review is to present current perspectives on the epidemiological relationship between MetS and gynecologic cancer. We will also review whether specific mechanisms that distinguish them from other types of cancer affect the development of gynecologic cancer. In addition, we will explore the effects of MetS on the morbidity and mortality of this cancer.

\section{Metabolic syndrome components and risk of cancer in women}

The pathophysiological mechanisms through which obesity, dyslipidemia, and hyperglycemia contribute to carcinogenesis are clearer than the mechanism correlating hypertension to carcinogenesis. The effects of these components on the development of cancer, especially on the gynecologic cancer are briefly described in the following paragraphs.

\section{Obesity and cancer}

Central obesity, defined by increased waist circumference or increased body mass index (BMI), has been related to a higher incidence of many kinds of malignancies as well as to higher morbidity and mortality in those cancers [4].

In addition to energy storage, the adipose tissue functions as an endocrine organ that regulates the hormones and cytokines such as sex steroids, leptin, adipokines, tumor necrosis factor (TNF)-alpha, and plasminogen activator inhibitor-1 [5]. Disarrangements in the regulation of these substances and lack of capacity to store the extra free fatty acids in fatty cells leads to chronic inflammation and related carcinogenesis [6].

An association between obesity and increased cancer incidence has been reported for female-specific cancers including ovarian, endometrial, and breast cancer. For example, a recent prospective cohort study involving 1.2 million UK women showed that higher BMI was associated with an increased incidence of endometrial cancer (relative risk [RR] per 10 units, 2.89, 95\% confidence interval [Cl], 2.62-3.18), ovarian cancer (RR, 1.14; 95\% Cl, 1.03-1.27), and breast cancer in postmenopausal women (RR, 1.40; $95 \% \mathrm{Cl}, 1.31-$ 1.49) [7]. When considering the menopausal status, there was an increased risk of endometrial and breast cancer in women with menopause.

The mechanism by which adiposity contributes to the development of these cancers in women can be deduced as follows: in postmenopausal women, adipose tissue becomes the major organ synthesizing estrogens [8]. Accordingly, compared with normal postmenopausal women, obese postmenopausal women show increased total and free serum estrogen levels. In addition, increased central adiposity contributes to a reduction in hepatic synthesis and blood concentrations of sex hormone-binding globulin (SHBG) which results in an increased fraction of bioavailable estradiol. Estrogens contribute to either tumor development and progression by induction of cellular proliferation and inhibition of cell apoptosis through the estrogen receptor-a. Estrogens also stimulate angiogenesis through vascular endothelial growth factor secretion [9]. Moreover, carcinogenesis can be induced by the mutagenic effects of estrogen through genotoxic metabolites [10]. Epidemiological studies suggested that this increased concentration of circulating sex steroids could elucidate the correlations between anthropometric parameters reflecting obesity and the occurrence of endometrial cancer (both in pre and postmenopausal women) and breast cancer (only in postmenopausal women) $[11,12]$.

Increased adiposity in cancer patients may also have detrimental effects on treatment outcomes and mortality. For ex- 


\section{Obstetrics \& Gynecology Science}

Da Yong Lee, et al. Metabolic syndrome in gynecologic cancer

ample, obesity has been reported to be a negative prognostic factor for breast cancer [13].

\section{Hyperinsulinemia, hyperglycemia, and cancer}

Insulin resistance is considered as the most important mechanism involved in the relationship between obesity, hyperglycemia, and carcinogenesis. Chronic hyperinsulinemia is reported to be correlated with various types of cancer including endometrial and breast cancer [14].

Hyperinsulinemia caused by insulin resistance and subsequent hyperglycemia triggers carcinogenesis indirectly by increasing circulating levels of free insulin-like growth factor (IGF)-1. Receptors for insulin and IGF-1 are observed in most types of cancer tissues. The insulin receptor can activate signaling pathways that stimulate cancer cell proliferation, protect cancer cells from apoptotic stimulation, and promote invasion and metastasis of cancer cells. These receptors also stimulate normal cells including vascular smooth muscle cells to proliferate and migrate, and these process can promote cancer progression [15].

Along with this process, impaired glucose management and hyperglycemia can promote cancer cell proliferation. This theory is supported by the increased glucose transporting proteins such as glucose transporter-1 (GLUT-1) in the cancer cells to support high glucose demands for cancer growth [16].

High levels of glucose promote cancer cell invasion and metastasis through stimulation of epithelial-mesenchymal transition (EMT) which acts as a crucial pathway for the acquisition of migration, invasion, and pluripotent stem celllike phenotype [17]. A recent study proposed that the EMT phenotype and the expression of cancer stem cell markers in basal luminal breast cancer are induced by hyperglycemic status. These environments lead to a reduced generation of reactive oxygen species (ROS) and increased tumor cell survival. Hyperglycemia also acts as an important factor to support the rapid proliferation of cancer tissue [18]. Aggressively growing cancer tissues often are characterized by an increased expression of GLUT-1 resulting in elevated glucose uptake, a metabolic shift to anaerobe glycolysis and contributing to increased lactate production.

\section{Dyslipidemia and cancer}

Elevated triglyceride and suppressed HDL-cholesterol also act as risk factors for cancer. The mechanism by which hypertriglyceridemia stimulates cancer cell proliferation and promotes anti-apoptotic capacity is through the activation of ROS synthesis and DNA damage caused by this detrimental stress [3]. Several studies reported that hypertriglyceridemia has been associated with a higher prevalence of cervical cancer $[19,20]$ and postmenopausal breast cancer [21].

Epidemiological evidence supports the association of decreased HDL-cholesterol with certain types of cancer development. One large-scale population-based epidemiological study reported the correlation of cervical carcinoma with a low serum HDL-cholesterol level [22]. Low HDL-cholesterol serum levels were reported to be a risk factor for increased breast cancer in pre- and postmenopausal women. This status might imply an unfavorable hormonal status with particularly elevated estrogen levels especially in obese women [23].

\section{Endometrial cancer}

\section{Epidemiological correlation between metabolic syndrome and endometrial cancer}

Epidemiologic studies have reported correlations of endometrial cancer risk with each component of the MetS, including obesity, diabetes, and hypertension. Recently, Esposito et al. [24], meta-analyzed the existing studies to clarify the epidemiologic relationship. This analysis included 3,132 endometrial cancer patients, and MetS was correlated with a significantly increased risk of endometrial cancer in all studies (RR, 1.89; 95\% Cl, 1.34-2.67). Among the components of MetS, obesity (measured by waist circumference) was a major component that was significantly correlated with endometrial cancer than other components (e.g. diabetes or hypertension), and the effect of obesity alone was more pronounced than the entire metabolic syndrome. Besides, diabetes, hypertension and high serum level of triglycerides were significantly correlated with a higher risk for endometrial cancer. However, no significant correlation between low HDL-cholesterol and endometrial cancer was observed.

Trabert et al. [25], conducted a large population-based case-control study including 16,323 cases and 100,751 controls. This study reaffirmed the existing results; endometrial cancer risk was correlated with MetS with RR, $1.39(95 \% \mathrm{Cl}$, 1.32-1.47). Among the MetS components, overweight or obesity (RR, 1.95; $95 \% \mathrm{Cl}, 1.80-2.11)$, elevated fasting glucose (RR, 1.36; 95\% Cl, 1.30-1.43), high blood pressure (RR, $1.31 ; 95 \% \mathrm{Cl}, 1.25-1.36)$, and elevated serum triglycerides 


\section{Obstetrics \& Gynecology Science}

Vol. 63, No. 3, 2020

(RR, 1.13; 95\% Cl, 1.08-1.18) were significantly related with increased incidence of endometrial cancer.

In addition, the effects of MetS components on the treatment of endometrial cancer were investigated, and Ko et al. [26], reported that diabetes was related to an elevated incidence of recurrence and worse overall survival in women treated for type I endometrial cancer.

\section{Effects of metabolic syndrome on the pathophysiology of endometrial cancer}

Aromatization from androstenedione to estrogen is processed in adipose cells, and elevated free estrogen with decreased serum levels of SHBG are accompanied by obesity [27]. Diabetes and Insulin resistance are also correlated with decreased serum SHBG [28], which can promote increased levels of free estrogen. The pathophysiologic evidence for elevated free estrogen as a carcinogen is well described, especially in endometrial cancer. Constant mitogenic stimulation of the endometrium through chronic estrogen stimulation is thought to be a major factor. Moreover, the elevated IGF-1 in obesity and hyperinsulinemia has been related to cell proliferation and may play a role in the development of hyperplasia and neoplastic transformation of endometrial tissue. Endometrial tumor tissues are reported to express elevated levels of IGF-I and insulin receptors [29].

\section{Management of metabolic syndrome and prognosis of endometrial cancer}

Several epidemiologic studies have suggested that medications generally prescribed to patients with MetS have a positive effect on outcomes in endometrial cancer patients besides the hypoglycemic effect [30]. Clinical studies have shown that treatment with metformin was related to a decreased risk of mortality in patients with endometrial cancer $[31,32]$. One of the mechanisms of action is the activation of 5 '-adenosine monophosphate-activated protein kinase (AMPK) and concurrent inhibition of the mammalian target of rapamycin (mTOR) cascade which may contribute to antiproliferative effects of metformin $[33,34]$. Besides, several plausible mechanisms have been reported for the effects of metformin to restrain cancer growth. These potential mechanisms include liver kinase b1/AMPK pathway activation, inhibition of protein synthesis, induction of cell cycle arrest and apoptosis, decrease in serum insulin concentrations, activation of the immune system, and suppression of cancer stem cells [35]. Some authors reported that the treatment with metformin was correlated with favorable outcomes after chemotherapy by potentiating these pathways [36].

Statins are prescribed to decrease cholesterol levels in dyslipidemia patients to manage and prevent cardiovascular diseases. These agents inhibit the hydroxymethylglutaryl coenzyme A (HMG-CoA) reductase and blocks protein prenylation through the suppression of the mevalonate pathway. These result in the suppression of the downstream cholesterol biosynthesis pathway and inhibited production of many types of isoprenoid metabolites including farnesyl pyrophosphate and geranyl pyrophosphate. Isoprenoid biosynthesis is essential for a variety of cancer cell growth-related cellular processes and for the initiation of cancer cell metastasis. As a result, statins block these pathways which contribute to the anticancer activity [37]. Other mechanisms include the induction of tumor cell apoptosis [38], suppression of RhoA and other guanosine triphosphatase binding proteins which is upregulated in several human malignancies [39]. Based on these theoretical bases, Lavie et al. [40], reported that statins are associated with decreased cancer risk and improved survival in endometrial cancer. The risk reduction effect was observed when statins were administrated for more than 1 year before diagnosis.

\section{Cervical cancer}

\section{Epidemiological correlation between metabolic syndrome and cervical cancer}

Cervical cancer is the second most common malignancy among women all over the world with a majority of the cases observed in the developing countries. Previous epidemiological studies have shown correlations between different types of metabolic syndrome components and the incidence of cervical cancer $[19,41]$. However, there is not enough information about the correlation between MetS and cervical cancer compared to endometrial cancer. Though some epidemiological studies do suggest that the MetS is correlated with an elevated risk of cervical cancer.

Penaranda et al. [22] reported the outcome of a casecontrol study using data from the U.S. population survey analysis. Among 26,393,229 women, 585,924 (2.3\%) of this cohort (cases) declared a history of cervical cancer. Among them, $48.6 \%$ of individuals met the MetS criteria compared 


\section{Obstetrics \& Gynecology Science}

Da Yong Lee, et al. Metabolic syndrome in gynecologic cancer

to $33.2 \%$ of controls ( $P=0.0768)$. Logistic regression analysis reported that cervical cancer patients had higher odds of MetS in both unadjusted (odds ratio [OR], 1.91; $95 \% \mathrm{Cl}$, 1.06-3.42), $P=0.0309$ ), and covariates adjusted patients, including multiple lifetime sexual partners, higher parity, hormonal contraceptive use, and history of smoking (adjusted $\mathrm{OR}, 1.82 ; 95 \% \mathrm{Cl}, 1.02-3.26 ; P=0.0428)$. When each component of the MetS was analyzed separately, none of the specific components were significantly correlated with cervical cancer. Ulmer et al. [42], reported the results of a prospective cohort during mean follow up duration of 11 years. Among 288,834 cohort population, 425 cases of invasive cervical cancer were diagnosed. According to Cox proportional hazards regression model analysis, the MetS score was correlated with $26 \%$ elevated corrected risk of cervical cancer. Triglyceride levels revealed higher association with squamous cell cervical carcinoma (hazard ratio [HR], 1.48; 95\% $\mathrm{Cl}, 1.20-1.83)$ than with adenocarcinoma (HR, 0.92; $95 \%$ $\mathrm{Cl}, 0.54-1.56)$. Compared with the results of Penaranda et al. [22], individual MetS components of obesity, higher blood pressure, and serum triglycerides respectively were correlated with increased incidence of cervical cancer.

According to these results, women with MetS would have an increased risk of experiencing cervical cancer compared to women without MetS. In the pathophysiological aspect, estrogen, adipokine, and cytokine have been reported to be correlated with cervical cancer suggesting metabolic syndrome components could act as cofactors in the carcinogenesis of cervical carcinoma $[43,44]$. These preceding associations support the growing body of evidence that there is a pathophysiologic correlation between metabolic disarrangements observed in MetS and carcinogenesis of cervical cancer.

\section{Effects of metabolic syndrome on the development of cervical cancer through the human papilloma virus}

Previous epidemiologic studies suggested that MetS may play a role in virus and host interactions which is essential for persistent human papilloma virus (HPV) infection. This interaction is a fundamental factor in the development of cervical cancer. The causal correlation between infection with the HPV and the progress of cervical cancer has been established through decades of accumulated evidence.

Recent studies explored the influence of MetS on HPV infection among women. Huang et al., reported that the morbidity of MetS increased the risk of HPV infection in females (RR, 1.25; 95\% Cl, 1.09-1.46) [45]. Molokwu et al. [46], studied a male cohort that could serve as mediators of both the HPV and the female population. In this report, MetS was reported to be significantly correlated with an elevated risk of HPV 6, 11, 16, or 18 infection in the total cohort (RR, 1.24; $95 \% \mathrm{Cl}, 1.03-1.48)$ and in the female cohort (RR, 1.26; $95 \% \mathrm{Cl}, 1.02-1.56)$ [46]. However, some controversy also exists, as Liu et al. [47] reported there was no significant relationship between MetS and HPV infection among females. In a study examining the risk factors of cytological progression in Korean women infected with HPV 16, women with $\mathrm{BMI} \geq 25$ showed a relative risk of 1.71 compared to women with $\mathrm{BMI}<25$, but there was no statistical significance $(95 \%$ $\mathrm{Cl}, 0.45-6.47)$ [48]. The study was based on fewer than 100 subjects, so larger studies will be needed to obtain clearer conclusions.

There are some pathophysiological evidence indicating that MetS components could promote carcinogenesis. An increase of adipokines (e.g., resistin), inflammatory markers (e.g., soluble Fas), and cytokines (e.g. interleukin [IL]6, TNF-a) has been observed in women with persistent HPV infection $[44,49]$. These reports suggest that obesity is correlated with persistent HPV infection. Pathophysiologic mechanisms through which hypertension increases the risk for HPV infection include hypertension-induced hypoxia, which in turn promotes angiogenesis through activation of hypoxia-inducible factor-1 [50]. This activation of angiogenesis has been described as a crucial pathway for the persistent infection and progression of the HPV lesions by supporting increased requirements of growing HPV lesions for nutrients and oxygen [51]. Insulin and IGFs stimulate invasive potential and proliferation of cervical cancer cells and were reported to be correlated with HPV infection [52]. Animal model from mouse reveals that estrogen and its nuclear receptor contribute to the initiation of cervical carcinogenesis by synergistic effect with the HPV oncogene [43].

\section{Effects of metabolic syndrome on the prognosis of cervical cancer treatment}

To investigate the effect of MetS on prognosis of cervical cancer after treatment, Ahn et al. [53], reported the correlation between MetS and recurrence-free survival (RFS) in patients with early-stage cervical cancer through a retro- 


\section{Obstetrics \& Gynecology Science}

Vol. 63, No. 3, 2020

spective study which assessed the patients diagnosed with the International Federation of Gynecology and Obstetrics (FIGO) stage I-II cervical cancer [53]. According to the study, RFS was not significantly different based on the presence of MetS. Among the components of MetS, hypertriglyceridemia $(\mathrm{HR}, 3.67 ; 95 \% \mathrm{Cl}, 1.18-11.43)$ and higher fasting glucose $(\mathrm{HR}, 4.30 ; 95 \% \mathrm{Cl}, 1.23-15.03)$ were suggested as independent risk factors for decreased RFS after adjustment for possible compounding factors. However, there is little epidemiological data available so far, and prospective validation in large populations is warranted.

\section{Ovarian cancer}

\section{Epidemiological correlation between metabolic syndrome and ovarian cancer}

Compared to other gynecologic cancers, there are relatively few studies that have directly analyzed the correlation between MetS and incidence of ovarian cancer. Although, there are some reports that analyzed the correlation between specific components of MetS and ovarian cancer.

Obesity has been reported to be correlated with the occurrence of ovarian cancer. The Collaborative Group on Epidemiological Studies of Ovarian Cancer performed a meta-analysis of 47 studies including 25,157 cases of ovarian cancer and reported a $10 \%$ increase in ovarian cancer risk per $5 \mathrm{~kg} / \mathrm{m}^{2}$ [54]. A prospective cohort study on 70,258 Chinese women addressed that women with a BMI of 30 or above had a 2-fold increased risk of ovarian cancer [55]. On the other hand, there is some controversy. Olsen et al. [56], analyzed studies from medical centers in the Ovarian Cancer Association Consortium and reported that elevated BMI was not correlated with high grade serous ovarian cancer.

Moreover, there are studies proposing that obesity may also be correlated with decreased overall survival in ovarian cancer patients. The meta-analysis of 14 studies analyzed by Protani et al. [57], presented a slightly decreased survival rate among obese women than in non-obese women (pooled HR, 1.17; $95 \% \mathrm{Cl}, 1.03-1.34)$. High leptin to adiponectin ratio was associated with decreased survival rate as observed in colorectal, breast, gastric and renal cancers [58]. Pavelka et al. [59], reported that in patients with advanced stages of ovarian cancer, obesity was independently associated with both shorter time to recurrence and lower overall survival. How- ever, the effects of MetS on the prognosis of ovarian cancer are controversial. There are also studies reporting that obese women had a better prognosis after treatment for ovarian cancer [60]. According to a previous study showing higher rates of residual disease after debulking surgery in women with low BMI [61], factors other than MetS metabolic components may affect the prognosis after cancer treatment.

There is relatively little information analyzing the effects of diabetes on ovarian cancer incidence and prognosis. Shah et al. [62], analyzed 367 patients with epithelial ovarian cancer in the U.S. and reported that diabetes was correlated with an elevated risk of recurrence and mortality in women with ovarian cancer.

As described, the respective effects of obesity and diabetes on ovarian cancer risk have been analyzed, and it could be expected that MetS would increase the incidence of ovarian cancer. Although, there is still insufficient evidence on the effects of MetS on ovarian cancer risk and whether it is more obvious than the individual effects of obesity and diabetes. The process of revealing this relationship through populationbased analysis is required for the future.

\section{Effects of metabolic syndrome on the progression and metastasis of ovarian cancer}

The etiological association between obesity, diabetes, and ovarian cancer is not clear, however, the available data provide some clues. According to a previous study, direct interactions between adipocytes and cancer cells have been suggested to stimulate tumor growth. For example, omental tissue is the most common site of ovarian cancer metastasis and secretion of cytokines such as IL- 6 and IL- 8 produced by adipocytes in the omentum has been reported to promote homing, migration, and invasion of ovarian cancer cells [63]. Moreover, secretion of free fatty acids originated from elevated lipolysis in omental adipocytes has been suggested as an energy source for proliferating ovarian cancer metastasis.

As described above, insulin resistance is associated with decreased serum SHBG and elevated free estrogen. A recent experimental study on the murine model suggested that elevated estrogen may play a role in promoting ovarian cancer growth [64].

\section{Management of metabolic syndrome and prognosis of ovarian cancer}

Preceding retrospective studies reported that the use of met- 


\section{Obstetrics \& Gynecology Science}

Da Yong Lee, et al. Metabolic syndrome in gynecologic cancer

formin, statins, and beta-blockers is correlated with better prognosis in ovarian cancer treatment.

A meta-analysis of existing observational studies reported that metformin may decrease the incidence of ovarian cancer in diabetic patients with an odds ratio of $0.57(95 \% \mathrm{Cl}$, $0.16-1.99)$ [65]. The studies analyzing the effects on survival rates reported that metformin may improve overall, diseasespecific, and progression-free survival after ovarian cancer treatment [65]. In vitro study suggested that metformin significantly suppresses the growth of ovarian cancer cell lineages and potentiates the therapeutic effect of cisplatin through its anti-proliferative property [66]. These findings suggest the possible therapeutic effects of metformin on the prevention and prognosis of ovarian cancer. Although, most of the existing evidence was retrospective observational studies with small subjects.

As discussed in endometrial cancer, statins block the pathways related to carcinogenesis and may contribute to the anticancer activity. Lavie et al. [40], reported that the treatment with statins possibly reduces the incidence of ovarian malignancies and improves the survival rate.

Stress hormones may stimulate ovarian cancer progression through multiple mechanisms including autonomic nervous system mediators such as epinephrine and norepinephrine $[67,68]$. These signals significantly elevate vascular endothelial growth factor and matrix metalloproteinase production which contribute to carcinogenesis and cancer progression. Beta-blockers used to manage hypertension, inhibit the production of these unfavorable adrenergic hormones, and are proved to be correlated with better survival in several cancers [69,70]. Based on this background, Diaz et al. [71], performed a retrospective study and reported that the use of beta-blockers correlated with decreased risk of recurrence and overall survival in women with ovarian cancer.

\section{Conclusions}

Preceding epidemiological data have reported a correlation between MetS or its diagnostic components and gynecologic cancer development and prognosis. Each component of MetS and associated metabolic disarrangements are proved to have a correlation with cancer development through experimental studies. However, it is still being debated whether the effects of each component are additive or synergistic. In this situation, further epidemiological and experimental studies are essential to clarify these findings.

Several clinical studies postulated that medications used to manage MetS have a preventive effect on cancer development. In addition, some clinical and experimental studies suggested the favorable effect of these medications on the prognosis, morbidity, and mortality of cancer treatment.

In view of these existing findings, addressing and managing MetS should be a part of the strategies undertaken to prevent and treat gynecologic cancer. So far, only limited data is available, and further clinical and fundamental research is required for robust conclusions.

\section{Acknowledgements}

The research was supported by fund from Korean Society of Obstetrics and Gynecology and grant number (03-2019-20) in Seoul Metropolitan Government-Seoul National University Boramae Medical Center.

\section{Conflict of interest}

No potential conflict of interest relevant to this article was reported.

\section{References}

1. Alberti KG, Eckel RH, Grundy SM, Zimmet PZ, Cleeman JI, Donato KA, et al. Harmonizing the metabolic syndrome: a joint interim statement of the International Diabetes Federation Task Force on Epidemiology and Prevention; National Heart, Lung, and Blood Institute; American Heart Association; World Heart Federation; International Atherosclerosis Society; and International Association for the Study of Obesity. Circulation 2009;120:1640-5.

2. Hong AR, Lim S. Clinical characteristics of metabolic syndrome in Korea, and its comparison with other Asian countries. J Diabetes Investig 2015;6:508-15.

3. Cowey S, Hardy RW. The metabolic syndrome: a highrisk state for cancer? Am J Pathol 2006;169:1505-22.

4. Renehan AG, Tyson M, Egger M, Heller RF, Zwahlen M. 


\section{Obstetrics \& Gynecology Science}

Vol. 63, No. 3, 2020

Body-mass index and incidence of cancer: a systematic review and meta-analysis of prospective observational studies. Lancet 2008;371:569-78.

5. Lee SW, Cho HH, Kim MR, Kwon DJ, Kim EJ, You YO, et al. The relationship between serum leptin level and metabolic syndrome in postmenopausal women. Korean J Obstet Gynecol 2010;53:254-63.

6. van Kruijsdijk RC, van der Wall E, Visseren FL. Obesity and cancer: the role of dysfunctional adipose tissue. Cancer Epidemiol Biomarkers Prev 2009;18:2569-78.

7. Reeves GK, Pirie K, Beral V, Green J, Spencer E, Bull D, et al. Cancer incidence and mortality in relation to body mass index in the Million Women Study: cohort study. BMJ 2007;335:1134.

8. Calle EE, Kaaks R. Overweight, obesity and cancer: epidemiological evidence and proposed mechanisms. Nat Rev Cancer 2004;4:579-91.

9. lyengar NM, Hudis CA, Dannenberg AJ. Obesity and cancer: local and systemic mechanisms. Annu Rev Med 2015;66:297-309.

10. Yager JD, Davidson NE. Estrogen carcinogenesis in breast cancer. N Engl J Med 2006;354:270-82.

11. Flötotto T, Djahansouzi S, Gläser $M$, Hanstein B, Niederacher $D$, Brumm $C$, et al. Hormones and hormone antagonists: mechanisms of action in carcinogenesis of endometrial and breast cancer. Horm Metab Res 2001;33:451-7.

12. Dickson RB, Stancel GM. Chapter 8: Estrogen receptormediated processes in normal and cancer cells. JNCI Monogr 2000;2000:135-45.

13. Carmichael AR. Obesity and prognosis of breast cancer. Obes Rev 2006;7:333-40.

14. Jee SH, Kim HJ, Lee J. Obesity, insulin resistance and cancer risk. Yonsei Med J 2005;46:449-55.

15. lyengar NM, Gucalp A, Dannenberg AJ, Hudis CA. Obesity and cancer mechanisms: tumor microenvironment and inflammation. J Clin Oncol 2016;34:4270-6.

16. Macheda ML, Rogers S, Best JD. Molecular and cellular regulation of glucose transporter (GLUT) proteins in cancer. J Cell Physiol 2005;202:654-62.

17. Iwatsuki M, Mimori K, Yokobori T, Ishi H, Beppu T, Nakamori $\mathrm{S}$, et al. Epithelial-mesenchymal transition in cancer development and its clinical significance. Cancer Sci 2010;101:293-9.

18. Masur K, Vetter C, Hinz A, Tomas N, Henrich H, Nigge- mann B, et al. Diabetogenic glucose and insulin concentrations modulate transcriptome and protein levels involved in tumour cell migration, adhesion and proliferation. Br J Cancer 2011;104:345-52.

19. Ulmer H, Borena W, Rapp K, Klenk J, Strasak A, Diem $G$, et al. Serum triglyceride concentrations and cancer risk in a large cohort study in Austria. Br J Cancer 2009;101:1202-6.

20. Tulinius H, Sigfússon N, Sigvaldason H, Bjarnadóttir K, Tryggvadóttir L. Risk factors for malignant diseases: a cohort study on a population of 22,946 Icelanders. Cancer Epidemiol Biomarkers Prev 1997;6:863-73.

21. Gaard M, Tretli S, Urdal P. Risk of breast cancer in relation to blood lipids: a prospective study of 31,209 Norwegian women. Cancer Causes Control 1994;5:501-9.

22. Penaranda EK, Shokar N, Ortiz M. Relationship between metabolic syndrome and history of cervical cancer among a US national population. ISRN Oncol 2013;2013:840964.

23. Kucharska-Newton AM, Rosamond WD, Mink PJ, Alberg AJ, Shahar E, Folsom AR. HDL-cholesterol and incidence of breast cancer in the ARIC cohort study. Ann Epidemiol 2008;18:671-7.

24. Esposito K, Chiodini P, Capuano A, Bellastella G, Maiorino MI, Giugliano D. Metabolic syndrome and endometrial cancer: a meta-analysis. Endocrine 2014;45:28-36.

25. Trabert B, Wentzensen N, Felix AS, Yang HP, Sherman ME, Brinton LA. Metabolic syndrome and risk of endometrial cancer in the united states: a study in the SEERmedicare linked database. Cancer Epidemiol Biomarkers Prev 2015;24:261-7.

26. Ko EM, Walter P, Clark L, Jackson A, Franasiak J, Bolac C, et al. The complex triad of obesity, diabetes and race in type I and II endometrial cancers: prevalence and prognostic significance. Gynecol Oncol 2014;133:28-32.

27. Forney JP, Milewich L, Chen GT, Garlock JL, Schwarz BE, Edman CD, et al. Aromatization of androstenedione to estrone by human adipose tissue in vitro. Correlation with adipose tissue mass, age, and endometrial neoplasia. J Clin Endocrinol Metab 1981;53:192-9.

28. Wallace IR, McKinley MC, Bell PM, Hunter SJ. Sex hormone binding globulin and insulin resistance. Clin Endocrinol (Oxf) 2013;78:321-9.

29. Fader AN, Arriba LN, Frasure HE, von Gruenigen VE. Endometrial cancer and obesity: epidemiology, bio- 


\section{Obstetrics \& Gynecology Science}

Da Yong Lee, et al. Metabolic syndrome in gynecologic cancer

markers, prevention and survivorship. Gynecol Oncol 2009;114:121-7.

30. Evans JM, Donnelly LA, Emslie-Smith AM, Alessi DR, Morris AD. Metformin and reduced risk of cancer in diabetic patients. BMJ 2005;330:1304-5.

31. Wu JW, Boudreau DM, Park Y, Simonds NI, Freedman AN. Commonly used diabetes and cardiovascular medications and cancer recurrence and cancer-specific mortality: a review of the literature. Expert Opin Drug Saf 2014;13:1071-99.

32. Zhang ZJ, Li S. The prognostic value of metformin for cancer patients with concurrent diabetes: a systematic review and meta-analysis. Diabetes Obes Metab 2014;16:707-10.

33. Rattan R, Ali Fehmi R, Munkarah A. Metformin: an emerging new therapeutic option for targeting cancer stem cells and metastasis. J Oncol 2012;2012:928127.

34. Cantrell LA, Zhou C, Mendivil A, Malloy KM, Gehrig PA, Bae-Jump VL. Metformin is a potent inhibitor of endometrial cancer cell proliferation--implications for a novel treatment strategy. Gynecol Oncol 2010;116:92-8.

35. Kourelis TV, Siegel RD. Metformin and cancer: new applications for an old drug. Med Oncol 2012;29:1314-27.

36. Hanna RK, Zhou C, Malloy KM, Sun L, Zhong Y, Gehrig PA, et al. Metformin potentiates the effects of paclitaxel in endometrial cancer cells through inhibition of cell proliferation and modulation of the mTOR pathway. Gynecol Oncol 2012;125:458-69.

37. Gazzerro P, Proto MC, Gangemi G, Malfitano AM, Ciaglia E, Pisanti $S$, et al. Pharmacological actions of statins: a critical appraisal in the management of cancer. Pharmacol Rev 2012;64:102-46.

38. Martirosyan A, Clendening JW, Goard CA, Penn LZ. Lovastatin induces apoptosis of ovarian cancer cells and synergizes with doxorubicin: potential therapeutic relevance. BMC Cancer 2010;10:103.

39. Horiuchi A, Kikuchi N, Osada R, Wang C, Hayashi A, Nikaido $T$, et al. Overexpression of RhoA enhances peritoneal dissemination: RhoA suppression with Lovastatin may be useful for ovarian cancer. Cancer Sci 2008:99:2532-9.

40. Lavie O, Pinchev M, Rennert HS, Segev Y, Rennert G. The effect of statins on risk and survival of gynecological malignancies. Gynecol Oncol 2013;130:615-9.

41. Lacey JV Jr, Swanson CA, Brinton LA, Altekruse SF,
Barnes WA, Gravitt PE, et al. Obesity as a potential risk factor for adenocarcinomas and squamous cell carcinomas of the uterine cervix. Cancer 2003;98:814-21.

42. Ulmer H, Bjørge T, Concin H, Lukanova A, Manjer J, Hallmans $\mathrm{G}$, et al. Metabolic risk factors and cervical cancer in the metabolic syndrome and cancer project (Me-Can). Gynecol Oncol 2012;125:330-5.

43. Chung SH, Franceschi S, Lambert PF. Estrogen and ERa: culprits in cervical cancer? Trends Endocrinol Metab 2010;21:504-11.

44. Baker R, Dauner JG, Rodriguez AC, Williams MC, Kemp TJ, Hildesheim A, et al. Increased plasma levels of adipokines and inflammatory markers in older women with persistent HPV infection. Cytokine 2011;53:282-5.

45. Huang X, Zhao Q, Yang P, Li Y, Yuan H, Wu L, et al. Metabolic syndrome and risk of cervical human papillomavirus incident and persistent infection. Medicine (Baltimore) 2016;95:e2905.

46. Molokwu JC, Penaranda E, Lopez DS, Dwivedi A, Dodoo C, Shokar N. Association of metabolic syndrome and human papillomavirus infection in men and women residing in the United States. Cancer Epidemiol Biomarkers Prev 2017;26:1321-7.

47. Liu SH, Chen HJ, Hsieh TH, Chen JC, Huang YC. Excessive adiposity, metabolic health, and risks for genital human papillomavirus infection in adult women: a population-based cross-sectional study. BMC Obes 2015;2:39.

48. So KA, Kim SA, Lee YK, Lee IH, Lee KH, Rhee JE, et al. Risk factors for cytological progression in HPV 16 infected women with ASC-US or LSIL: the Korean HPV cohort. Obstet Gynecol Sci 2018;61:662-8.

49. Kemp TJ, Hildesheim A, García-Piñeres A, Williams MC, Shearer GM, Rodriguez AC, et al. Elevated systemic levels of inflammatory cytokines in older women with persistent cervical human papillomavirus infection. Cancer Epidemiol Biomarkers Prev 2010;19:1954-9.

50. Bárdos J, Ashcroft M. Negative and positive regulation of HIF-1: a complex network. Biochim Biophys Acta 2005;1755:107-20.

51. Bodily J, Laimins LA. Persistence of human papillomavirus infection: keys to malignant progression. Trends Microbiol 2011;19:33-9.

52. Serrano ML, Sánchez-Gómez M, Bravo MM. Cervical scrapes levels of insulin-like growth factor-II and insulinlike growth factor binding protein 3 in women with 


\title{
Obstetrics \& Gynecology Science
}

\author{
Vol. 63, No. 3, 2020
}

squamous intraepithelial lesions and cervical cancer. Horm Metab Res 2010;42:977-81.

53. Ahn HK, Shin JW, Ahn HY, Park CY, Lee NW, Lee JK, et al. Metabolic components and recurrence in early-stage cervical cancer. Tumour Biol 2015;36:2201-7.

54. Collaborative Group on Epidemiological Studies of Ovarian Cancer. Ovarian cancer and body size: individual participant meta-analysis including 25,157 women with ovarian cancer from 47 epidemiological studies. PLoS Med 2012;9:e1001200.

55. Ma X, Beeghly-Fadiel A, Shu XO, Li H, Yang G, Gao $\mathrm{YT}$, et al. Anthropometric measures and epithelial ovarian cancer risk among Chinese women: results from the Shanghai Women's Health Study. Br J Cancer 2013;109:751-5.

56. Olsen CM, Nagle CM, Whiteman DC, Ness R, Pearce $C L$, Pike $M C$, et al. Obesity and risk of ovarian cancer subtypes: evidence from the Ovarian Cancer Association Consortium. Endocr Relat Cancer 2013;20:251-62.

57. Protani MM, Nagle CM, Webb PM. Obesity and ovarian cancer survival: a systematic review and meta-analysis. Cancer Prev Res (Phila) 2012;5:901-10.

58. Diaz ES, Karlan BY, Li AJ. Obesity-associated adipokines correlate with survival in epithelial ovarian cancer. Gynecol Oncol 2013;129:353-7.

59. Pavelka JC, Brown RS, Karlan BY, Cass I, Leuchter RS, Lagasse LD, et al. Effect of obesity on survival in epithelial ovarian cancer. Cancer 2006;107:1520-4.

60. Bae HS, Hong JH, Ki KD, Song JY, Shin JW, Lee JM, et al. The effect of body mass index on survival in advanced epithelial ovarian cancer. J Korean Med Sci 2014;29:793-7.

61. Son JH, Chang K, Kong TW, Paek J, Chang SJ, Ryu HS. A study of clinicopathologic factors as indicators for early prediction of suboptimal debulking surgery after neoadjuvant chemotherapy in advanced ovarian cancer. J Obstet Gynaecol Res 2018;44:1294-301.

62. Shah MM, Erickson BK, Matin T, McGwin G Jr, Martin
JY, Daily LB, et al. Diabetes mellitus and ovarian cancer: more complex than just increasing risk. Gynecol Oncol 2014;135:273-7.

63. Nieman KM, Kenny HA, Penicka CV, Ladanyi A, BuellGutbrod R, Zillhardt MR, et al. Adipocytes promote ovarian cancer metastasis and provide energy for rapid tumor growth. Nat Med 2011;17:1498-503.

64. Laws MJ, Kannan A, Pawar S, Haschek WM, Bagchi MK, Bagchi IC. Dysregulated estrogen receptor signaling in the hypothalamic-pituitary-ovarian axis leads to ovarian epithelial tumorigenesis in mice. PLoS Genet 2014;10:e1004230.

65. Dilokthornsakul P, Chaiyakunapruk N, Termrungruanglert W, Pratoomsoot C, Saokaew S, Sruamsiri R. The effects of metformin on ovarian cancer: a systematic review. Int J Gynecol Cancer 2013;23:1544-51.

66. Gotlieb WH, Saumet J, Beauchamp MC, Gu J, Lau S, Pollak MN, et al. In vitro metformin anti-neoplastic activity in epithelial ovarian cancer. Gynecol Oncol 2008; 110:246-50.

67. Sood AK, Bhatty R, Kamat AA, Landen CN, Han L, Thaker $\mathrm{PH}$, et al. Stress hormone-mediated invasion of ovarian cancer cells. Clin Cancer Res 2006;12:369-75.

68. Lutgendorf SK, Cole S, Costanzo E, Bradley S, Coffin J, Jabbari $\mathrm{S}$, et al. Stress-related mediators stimulate vascular endothelial growth factor secretion by two ovarian cancer cell lines. Clin Cancer Res 2003;9:4514-21.

69. Barron TI, Connolly RM, Sharp L, Bennett K, Visvanathan K. Beta blockers and breast cancer mortality: a population- based study. J Clin Oncol 2011;29:2635-44.

70. Powe DG, Voss MJ, Zänker KS, Habashy HO, Green AR, Ellis IO, et al. Beta-blocker drug therapy reduces secondary cancer formation in breast cancer and improves cancer specific survival. Oncotarget 2010;1:628-38.

71. Diaz ES, Karlan BY, Li AJ. Impact of beta blockers on epithelial ovarian cancer survival. Gynecol Oncol 2012;127:375-8. 